\title{
Time Elapsed from AML Diagnosis to Induction Chemotherapy Affects Overall Survival*
}

\author{
Luís Arthur Flores Pelloso ${ }^{1,2}$, Sandra Serson Rohr ${ }^{1}$, Mihoko Yamamoto ${ }^{1}$, \\ Maria de Lourdes L. Ferrari Chauffaille ${ }^{1}$
}

${ }^{1}$ Section of Hematology and Blood Transfusion, Department of Clinical and Experimental Oncology, Federal University of São Paulo (UNIFESP-EPM), São Paulo, Brazil; ${ }^{2}$ Pharmacovigilance, Pharmaceutical Product Development, Inc., São Paulo, Brazil. Email: chauffaille@unifesp.br

Received May $15^{\text {th }}, 2013$; revised June $13^{\text {th }}, 2013$; accepted June $20^{\text {th }}, 2013$

Copyright (C 2013 Luís Arthur Flores Pelloso et al. This is an open access article distributed under the Creative Commons Attribution License, which permits unrestricted use, distribution, and reproduction in any medium, provided the original work is properly cited.

\begin{abstract}
We aimed to study the effect of elapsed time from AML diagnosis to treatment (TDT) on OS in a group of patients from public Hospital in Brazil. 41 AML (23 M, 18 F, 41 yrs, 18 - 84 yrs, from 2001 to 2004). There were 38 de novo AML and 3 secondary, median TDT was 6 days (range $1-82 \mathrm{~d}$ ); the young ones were treated earlier than old ones (TDT 4 days vs $11, \mathrm{p}=0.07)$. Longer TDT $(>10 \mathrm{~d})$ was associated with worse CR rates $(\mathrm{p}=0.02)$ and OS $(\mathrm{p}=0.04)$. When patients were categorized into TDT from $1-4 \mathrm{~d}$ (I) vs $>5$ (II), those from I presented better OS than II $(\mathrm{p}=$ 0.004). When TDT was longer than 7 days OS decreased even more. Hb was higher in patients with TDT I vs II (8.3 vs $7.5 \mathrm{~g} / \mathrm{dL}, \mathrm{p}=0.03)$ but WBC $(\mathrm{p}=0.34)$ and platelet count $(\mathrm{p}=0.75)$ were not different. Patients with TDT of $10 \mathrm{~d}$ were younger than TDT $>10 \mathrm{~d}$ (median age $41 \mathrm{vs} 70 \mathrm{yrs}, \mathrm{p}=0.001$ ). The OS was $15.1 \%$ in 2 yrs and $8.6 \%$ in 7 yrs. Our data suggest longer TDT, when analyzed continuously, predicted for lower CR rates and OS rates.
\end{abstract}

Keywords: Acute Myeloid Leukemia; Karyotype; Time to Induction; Elderly AML; Prognostic Factors

\section{Introduction}

Acute Myeloid Leukemia (AML) is a heterogeneous group of genetically diverse hematopoietic malignancies arising from blood cell progenitors. The management of AML represents a significant clinical challenge to haematologists and, although the incidence of the disease is relatively low, the clinical resources needed for its successful management are substantial (including, but not limited to early chemotherapy initiation, aggressive large broad antibiotic usage, early antifungal prescription, red blood cell and platelet transfusions) and consequently it is considered an oncologic emergency. The outcome for patients with AML depends greatly on the age of the patient and leukaemic cell karyotype and therefore different treatment strategies may be appropriate for different sub-groups of patients. To date, other key prognostic factors are FLT3-ITD status and response to induction chemotherapy [1-3]. Usually, AML patients present at diagnosis with severe infections and other worsening

${ }^{*}$ Conflict of interest disclosure: The authors declare no competing financial interests. medical conditions that demand prompt treatment [3]. Due to AML nature and the need for immediate treatment induction chemotherapy is given simultaneously during medical treatment of other conditions or shortdelayed until life-threatening conditions are treated and medically managed and stabilized.

With regards to the time elapsed from AML diagnosis to the start of induction chemotherapy few new data were published specially in emergent countries in which the overall context is very unique due to limited resources and availability of specialized hematological care [4-7]. In this paper we aimed to study retrospectively the effect of elapsed time from AML diagnosis to treatment (TDT) on overall survival OS in a group of patients from the public academic institution Hospital São Paulo, Brazil.

\section{Material and Methods}

Forty-one consecutively AML patients were consecutively studied (23 males and 18 females, median age: 41 yrs, range 18 - 84 yrs) from Jan 1st, 2001 to Mar 31st, 2004. Last overall survival assessment was done on Jul 
24th, 2011. AML diagnosis was set according to WHO classification and by G-banding karyotype (ISCN, 2009). Cytogenetic risk classification categories were adapted from MRC [1]. Patients were treated with $3+7$ daunorubicin $\left(45 \mathrm{mg} / \mathrm{m}^{2} / \mathrm{d} / 3 \mathrm{~d}\right)$, APL patients received ATRA-based regimen [8]. The study was approved by the institution ethics committee. Kaplan-Meier and student t-test were used.

\section{Results}

Initially fifty-eight consecutive patients were studied. However seventeen patients unfit for intent to treatment chemotherapy due to poor medical conditions and were managed with supportive care onlu (e.g. blood and platelet transfusions, antibiotics, management of medical conditions, hydroxurea in patients with leukcocytosis).

The remaining thirty-eitght patients were analysed given all of them received induction therapy. There were 38 patients with de novo AML and 3 secondary (Table 1), the median pretreatment WBC was $9.1 / \mu \mathrm{L}$ (range 0.5 - 240/ $\mu \mathrm{L}$ ), median TDT was 6 days (range 1 - 82 d); 26 patients were young ( $<60 \mathrm{yrs}$ ) and 15 old ( $>60 \mathrm{yrs}$ ) (Tables 2 and 5). Cytogenetic risk distribution was: favorable $20.7 \%$; intermediate $27.6 \%$; unfavorable $27.6 \%$ and no metaphases $27.6 \%$. Twenty patients achieved CR (48.7\%): $61.5 \%$ in the young and $26.6 \%$ in the elderly group, respectively. Median overall survival was significantly greater in young than elderly patients (291 vs 88 days, respectively, $\mathrm{p}=0.003$, Figure 1 and Tables 3-5). There were no statistical differences with regards to biological features (Hb, WBC and platelet count) between two age groups (Table 2). Interestingly, young patients tended to be treated earlier than old ones (TDT 4 days vs 11, $\mathrm{p}=0.07$ Table 5). Moreover, there was noticed an inverse correlation in TDT with age, leukocyte, CR and OS (Table 4). Longer TDT (>10 days) was associated

Table 1. Patient demographics.

\begin{tabular}{ccc}
\hline \multicolumn{2}{c}{ Characteristics } & AML patients n (\%) \\
\hline \multirow{2}{*}{ Total } & & 58 \\
Disease & AML de novo & $51(88.8 \%)$ \\
Sex & AML secondary & $7(12 \%)$ \\
Induction therapy & Male & $29(50.0 \%)$ \\
Complete remission & Female & $29(50.0 \%)$ \\
Cytogenetic risk group & Supportive care & 41 \\
& & 17 \\
& & $70.6 \%$ \\
& Favorable & $12(20.7 \%)$ \\
& Intermediate & $16(27.6 \%)$ \\
& Unfavorable & $14(24.1 \%)$ \\
& NA & $16(27.6 \%)$ \\
\hline
\end{tabular}

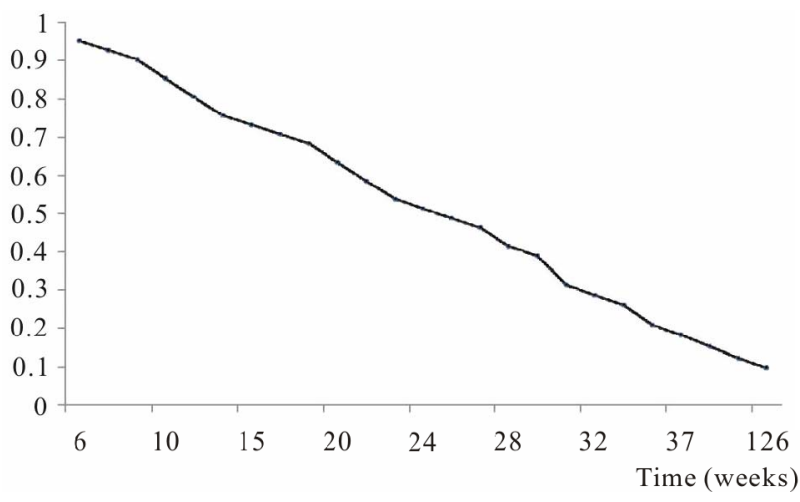

Figure 1. Cumulative overall survival in AML patients.

Table 2. Time to induction AML, overall survival and baseline hematology parameters.

\begin{tabular}{ccccccc}
\hline $\begin{array}{c}\text { Time to } \\
\text { induction } \\
\text { (days) }\end{array}$ & $\begin{array}{c}\text { Number } \\
\text { of } \\
\text { patients }\end{array}$ & $\begin{array}{c}\text { OS } \\
\text { (weeks) }\end{array}$ & $\begin{array}{c}\text { Median } \\
\text { age } \\
\text { (yrs) }\end{array}$ & $\begin{array}{c}\text { Mb } \\
\text { (g/dL) }\end{array}$ & $\begin{array}{c}\text { Median } \\
\text { leukocyte } \\
\times 10^{9} / 1\end{array}$ & $\begin{array}{c}\text { Median } \\
\text { platelet } \\
\times 10^{9} / 1\end{array}$ \\
\hline $\mathbf{1}$ & 5 & 285 & 41 & 8.1 & 8 & 38 \\
$\mathbf{2}$ & 6 & 122 & 45.5 & 7.7 & 9.65 & 63.5 \\
$\mathbf{3}$ & 3 & 37 & 50 & 8.9 & 12.1 & 35 \\
$\mathbf{4}$ & 4 & 181 & 35 & 6.15 & 8.1 & 59 \\
$\mathbf{5 - 6}$ & 4 & 161 & 48 & 8.15 & 8.4 & 42.5 \\
$\mathbf{7 - 9}$ & 6 & 26 & 56 & 5.3 & 18.7 & 44 \\
$\mathbf{7 1 0}$ & 13 & 11 & 70 & 6.9 & 3.9 & 53 \\
\hline
\end{tabular}

Table 3. Time to induction AML and overall survival.

\begin{tabular}{cccc}
\hline Time to induction (days) & Number of patients & OS (weeks) & $\mathrm{p}$ value \\
\hline $\mathbf{1}$ & 5 & 285 & \\
2 & 6 & 122 & \\
$\mathbf{3}$ & 3 & 37 & \\
$\mathbf{4}$ & 4 & 181 & \\
$\mathbf{5}-\mathbf{6}$ & 4 & 161 & \\
$\mathbf{7 - 9}$ & 6 & 26 & \\
$>\mathbf{1 0}$ & 13 & 11 & $\mathrm{p}=0.04$ \\
\hline
\end{tabular}

with poorer CR rates $(\mathrm{p}=0.02)$ and $\mathrm{OS}(\mathrm{p}=0.04)$. When patients were categorized into specific TDT groups: early ( 1 - 4 days: I) and late ( $>5$ days: II), those from I presented better OS than II $(p=0.004)$. When TDT was greater than 7 days OS decreased even more. Hb was relatively higher in patients with TDT I vs II (8.3 vs 7.5 $\mathrm{g} / \mathrm{dL}, \mathrm{p}=0.03)$ but WBC $(\mathrm{p}=0.34)$ and platelet count ( $\mathrm{p}$ $=0.75$ ) were not different. Patients with TDT of $10 \mathrm{~d}$ were younger than TDT $>10 \mathrm{~d}$ (median age 41 vs $70 \mathrm{yrs}$, $\mathrm{p}=0.001$ ). For the entire AML cohort OS was $15.1 \%$ in 2 yrs and $8.6 \%$ in 7 yrs.

\section{Discussion}

The results showed that less than half of the patients reached CR. Younger patients presented better CR than 
Table 4. Time to induction chemotherapy and complete remission.

\begin{tabular}{|c|c|c|c|c|c|}
\hline Time to induction (days) & Number of patients & Complete remission & $\mathrm{p}$ value & Comparison & $\mathrm{p}$ value \\
\hline 1 & 5 & $60 \%$ & & 1 - 4 days vs $>5$ days & 0.004152 \\
\hline 2 & 6 & $83.3 \%$ & 0.00993272 & & \\
\hline 3 & 3 & $66.6 \%$ & & & \\
\hline 4 & 4 & $50 \%$ & & & \\
\hline $5-6$ & 4 & $25 \%$ & & & \\
\hline $7-9$ & 6 & $33.3 \%$ & & & \\
\hline$>10$ & 13 & $38.4 \%$ & 0.47 & & \\
\hline
\end{tabular}

Table 5. Comparison between time to induction and age groups.

\begin{tabular}{|c|c|c|c|c|}
\hline & $<60$ years & $>60$ years old & total & $\mathrm{p}$ value \\
\hline Median days with complaints in medical history & 21 & 30 & 30 & 0.06 \\
\hline Median time to treatment & 4 days $(1-45)$ & 11 days $(2-82)$ & 6 days & 0.079 \\
\hline Median leukocyte $\times 10^{9} / 1$ & 9 & 9.3 & 9.25 & 0.79 \\
\hline Median $\mathrm{Hb}$ g/dL & 7 & 7.25 & 7.4 & 0.26 \\
\hline Median platelet $\times 10^{9} / 1$ & 38 & 27 & 51 & 0.33 \\
\hline Overall survival (days) & 291 & 88 & & 0.003 \\
\hline Favorable & 10 & 2 & 12 & \\
\hline Intermediate & 5 & 3 & 8 & \\
\hline Unfavorable & 6 & 3 & 9 & \\
\hline No metaphases & 5 & 7 & 12 & \\
\hline
\end{tabular}

elderly and this is similar to other series [3,5,9,10]. Despite chemotherapy regimen younger patients presented poorer OS compared to Northern Hemisphere patient series $[3,10]$. Several reasons may account for such results: poorer performance status at diagnosis, delayed diagnosis (patients could be seen elsewhere or given blood/platelet transfusions in other clinics), and presenting bleeding and infectious complications at diagnosis, advanced disease (severe marrow failure, poor physical reserve). Elderly patients who were treated presented dismal OS and notably a median TDT almost three times longer than younger. Reasons for a longer TDT in AML in the elderly group were: significant comorbidities, severe infectious complications, and delayed start chemotherapy due to logistics reasons (access to chemotherapy, the need to involve caregivers and family members to aid in decision-making process. With more comorbidity in elderly population, reluctance toward intensive therapy is common and probable medical decision is critical in this scenario. Thereupon measures to shorten the TDT should be taken: address a rapid AML diagnosis, evaluate and treat comorbidities, and develop a supportive and continuous system to promote early AML diagnosis and prompt treatment. Our data suggest that longer TDT, when analyzed continuously, predicted for lower CR rates and OS rates, hence we need to address identify factors and start therapeutic measures to aid decision making and improve OS in AML patients in our country.

\section{Authors and Affiliations}

Contribution: LAFP, wrote the paper, analysed data and followed up patients. MLC is in charge of the Leukemia Sector of Hematology Department and oriented treatment and follow up of patients as well as contributed to drawing the study and the paper. MY performed diagnosis, SSR analysed data.

\section{Acknowledgements}

This work was supported in part by the grant provided by Fapesp: 07-55665-6. MLC has Research grant supported by CNPq 309932/2009-2. This work was supported by the grant providedby CNPq (Conselho Nacional de Desenvolvimento Científico e Tecnológico). The fellowship grant supported by CNPq was Luís Arthur Flores Pelloso, process number 140232/2001-0, period 03/01/2001 to 02/28/2005.

\section{REFERENCES}

[1] D. Grimwade, H. Walker, G. Harrison, et al., "The Predictive Value of Hierarchical Cytogenetic Classification 
in Older Adults with Acute Myeloid Leukemia (AML): Analysis of 1065 Patients Entered into the United Kingdom Medical Research Council AML 11 Trial,” Blood, Vol. 98, No. 5, 2001, pp. 1312-1320.

doi:10.1182/blood.V98.5.1312

[2] P. D. Kottaridis and R. E. Gale, Frew "The Presence of a FLT3 Internal Tandem Duplication in Patients with Acute Myeloid Leukemia (AML) Adds Important Prognostic Information to Cytogenetic Risk Group and Response to the First Cycle of Chemotherapy: Analysis of $854 \mathrm{~Pa}-$ tients from the United Kingdom Medical Research Council AML 10 and 12 Trials,” Blood, Vol. 98, No. 6, 2001, pp. 1752-1759. doi:10.1182/blood.V98.6.1752

[3] M. A. Sekeres, P. Elson, M. E. Kaylacio, et al., "Time from Diagnosis to Treatment Initiation Predicts Survival in Younger, But Not Older, Acute Myeloid Leukemia Patients,” Blood, Vol. 113, No. 1, 2009, pp. 28-36. doi:10.1182/blood-2008-05-157065

[4] E. M. Fagundes, V. Rocha and A. B. Glória, et al., "De Novo Acute Myeloid Leukemia in Adults Younger than 60 Years of Age: Socioeconomic Aspects and Treatment Results in a Brazilian University Center," Leukemia \& Lymphoma, Vol. 47, No. 8, 2006, pp. 1557-1564. doi:10.1080/10428190600627055

[5] W. Pulcheri, N. Spector, M. Nucci, et al., "The Treatment of Acute Myeloid Leukemia in Brazil: Progress and Obstacles,” Haematologica, Vol. 80, No. 2, 1995, pp. 130-
135.

[6] L. A. Pelloso, M. de L. Chauffaille, F. S. Ghaname, et al., "Karyotype in Acute Myeloid Leukemia: Importance and Type of Aberrations in 30 Patients at Diagnosis," Revista da Associação Médica Brasileira, Vol. 49, No. 2, 2003, pp. 150-155. doi:10.1590/S0104-42302003000200032

[7] C. A. Rodrigues, M. L. Chauffaille, L. A. Pelloso, et al., "Acute Myeloid Leukemia in Elderly Patients: Experience of a Single Center," Brazilian Journal of Medical and Biological Research, Vol. 36, No. 6, 2003, pp. 703708. doi:10.1590/S0100-879X2003000600004

[8] A. Kanamaru, Y. Takemoto, M. Tanimoto, H. Muramaki, N. Asou, T. Kobayashi, K. Kuriyama, E. Ohmoto, H. Sakamaki, K. Tsubari, A. Hiraoka, O. Yamada, H. Oh, K. Saito, S. Matsuda, K. Minato, T. Ueda, O. Ohno and Japan Study Group, “All Trans Retinoic Acid for the Treatment of Newly Diagnosed Acute Promyelocytic Leukemia,” Blood, Vol. 85, No. 5, 1995, pp. 1202-1206.

[9] F. R. Appelbaum, H. Gundacker, D. R. Head, et al., "Age and Acute Myeloid Leukemia,” Blood, Vol. 107, No. 9, 2006, pp. 3481-3485. doi:10.1182/blood-2005-09-3724

[10] G. Juliusson, et al., "Most 70- to 79-Year-Old Patients with Acute Myeloid Leukemia Do Benefit from Intensive Treatment,” Blood, Vol. 117, No. 12, 2011, pp. 34733474. doi:10.1182/blood-2010-11-321737 